\title{
Engineering live cell surfaces with functional polymers via cytocompatible controlled radical polymerization
}

Jia Niu ${ }^{1,2}$, David J. Lunn ${ }^{2,8}$, Anusha Pusuluri ${ }^{3}$, Justin I. Yoo ${ }^{3}$, Michelle A. O'Malley ${ }^{3}$, Samir Mitragotri ${ }^{3,4}$, H. Tom Soh ${ }^{* 6,7}$, Craig J. Hawker ${ }^{* 1,2,4,5}$

1. California NanoSystems Institute,

2. Materials Research Laboratory,

3. Department of Chemical Engineering,

4. Center for Bioengineering,

5. Department of Chemistry and Biochemistry,

University of California, Santa Barbara, California 93106, United States

6. Department of Radiology, School of Medicine,

7. Department of Electrical Engineering,

Stanford University, Stanford, CA 94305, United States

8. Department of Chemistry, University of Oxford, Oxford OX1 3TA, United Kingdom

Correspondence to: hawker@mrl.ucsb.edu and tsoh@ stanford.edu

\begin{abstract}
The capability to graft synthetic polymers onto the surfaces of live cells offers the potential to manipulate and control their phenotype and underlying cellular processes. Conventional grafting-to strategies for conjugating preformed polymers to cell surfaces are limited by low polymer grafting efficiency. Here we report an alternative grafting-from strategy for directly engineering the surfaces of live yeast and mammalian cells through cell surface-initiated controlled radical polymerization. By developing cytocompatible PET-RAFT (photoinduced electron transfer-reversible addition-fragmentation chain transfer polymerization), synthetic polymers with narrow polydispersity ( $\mathrm{Mw} / \mathrm{Mn}<1.3$ ) could be obtained at room temperature in 5 minutes. This polymerization strategy enables chain growth to be initiated directly from chain transfer agents anchored on the surface of live cells using either covalent attachment or non-covalent insertion, while maintaining high cell viability. Compared to conventional grafting-to approaches, these methods significantly improve the efficiency of grafting polymer chains and enable the active manipulation of cellular phenotypes.
\end{abstract}


Engineering cell surfaces with synthetic macromolecules is a powerful approach for expanding the structural repertoire and properties of cells. Compared to small molecule cell surface modifications, grafting synthetic polymers provides a number of advantages associated with the increase in functional groups available for secondary interactions, derivatization, and changes in physical properties. As a result, the introduction of functional polymers for cell surface modification has been the focus of considerable research and development efforts over the past decade. ${ }^{1-5}$ Traditionally, such modification has primarily involved the physical or chemical conjugation of preformed polymers ('grafting-to', Figure 1a). ${ }^{1,6-18}$ However, this grafting-to approach is often limited by low polymer grafting on the cell surface and the use of a large excess of reactive polymers for functionalization. ${ }^{12,19}$ Direct encapsulation of cells within crosslinked networks has been examined but reduces the modified cell's capability of signal transduction and mass transport due to limited molecular access to the cell surface (Figure 1b). ${ }^{5,20-23}$ To overcome these challenges, 'grafting-from' strategies, in which structurally defined polymers are initiated directly from the cell surface, may offer improved polymer properties, ${ }^{24}$ including enhanced polymer grafting, controlled chain length and use of functional block copolymers, while still maintaining regular cell surface functions.

The significant synthetic challenges inherent in such 'grafting-from' strategies have in the past limited progress in this area. However, controlled radical polymerization (CRP) techniques have been shown to offer viable routes to polymer-biomolecule conjugates, especially for systems that are sensitive to chemical damage. These advantages are driven by the low concentration of radicals and low crossreactivity with biological functional groups and allows the use of CRP for the generation of protein and nucleic acid-based hybrid materials. ${ }^{25}$ Based on these promising initial studies, the translation of CRP to the extreme case of viable cell surface-initiated polymerization represents a noteworthy opportunity. Success requires the following three essential challenges to be overcome: (i) polymerization must achieve fast kinetics in aqueous solution at room temperature to minimize the exposure of cells to the potentially 
harmful polymerization environment; (ii) the presence of a small amount of oxygen must not inhibit the reaction, as rigorous degassing procedures such as 'freeze-pump-thaw' cycles cannot be used with live cells; and (iii) the polymerization reactants and conditions must not harm the cells.

a) Grafting-to polymer conjugation

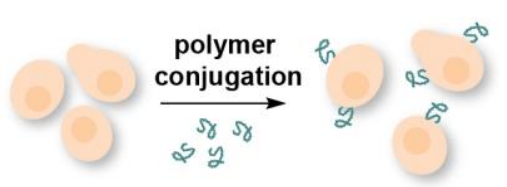

b) Cell encapsulation

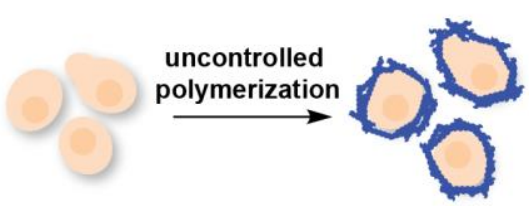

c) Cell surface-initiated CRP

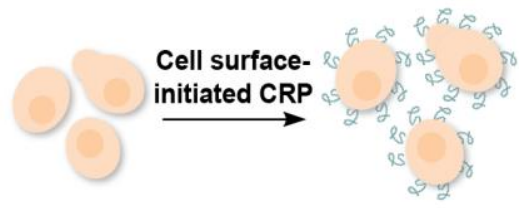

Figure 1. Strategies for engineering cell surfaces using synthetic polymers. (a) 'Grafting-to' methods tend to suffer from low grafting densities, whereas (b) existing 'grafting from' methods based on cell encapsulation do not enable control over the extent or structure of the grafted polymers. (c) Our controlled radical polymerization method offers a biocompatible technique for controlled addition of high densities of functional polymers to cell surfaces.

In this work, we report the first cytocompatible CRP techniques that can generate structurally defined synthetic polymers on live cell surfaces via a grafting-from approach (Figure 1c). Inspired by recent advancements in light-mediated CRP techniques - especially the photoinduced electron transferreversible addition-fragmentation chain transfer polymerization (PET-RAFT) method of Boyer and coworkers $^{26,27}$ - we developed a visible light-mediated PET-RAFT processes, from initiators that are either covalently attached or non-covalently inserted into the cell surface, for cytocompatible, cell surface-initiated polymerization. These strategies lead to an increase in the amount of grafted polymers directly on the cell surface when compared to traditional polymer grafting strategies and can also be used to incorporate a wide range of functional groups. This enables further post-polymerization functionalization of the cell surface and even modulation of cell-cell interactions.

\section{Results and Discussion}

\section{Cytocompatible PET-RAFT}


Our initial strategy involves polymerization from initiators covalently linked to the amino groups of the yeast cell surface proteins - analogous to the synthesis of polymer brushes from surface-bound initiators by CRP. ${ }^{28-32}$ In contrast to polymer brush generation on abiotic substrates (e.g., silicon wafers), polymerization from a living organism mandates the implementation of a rigorously biocompatible CRP process. We therefore examined the polymerization of acrylamide monomers, and polyethylene glycol (PEG)-based acrylamides in particular, as these have high polymer propagation rates in aqueous solutions at room temperature and good hydrolytic stability in biological environments. ${ }^{28,33-35} \mathrm{We}$ selected those with molecular weights $=1 \mathrm{kDa}$, as these materials have been shown to be impermeable to cell membranes. ${ }^{22,36}$ Eosin $\mathrm{Y}$ was chosen as the catalyst, with 2-(butylthiocarbonothioyl) propionic acid (BTPA) as the chain transfer agent (CTA) and triethanolamine as the co-catalyst for PET-RAFT in pH 7.4 PBS buffer. ${ }^{27,37}$ The polymerization results are summarized in Table 1.

Table 1. Results of PET-RAFT polymerization
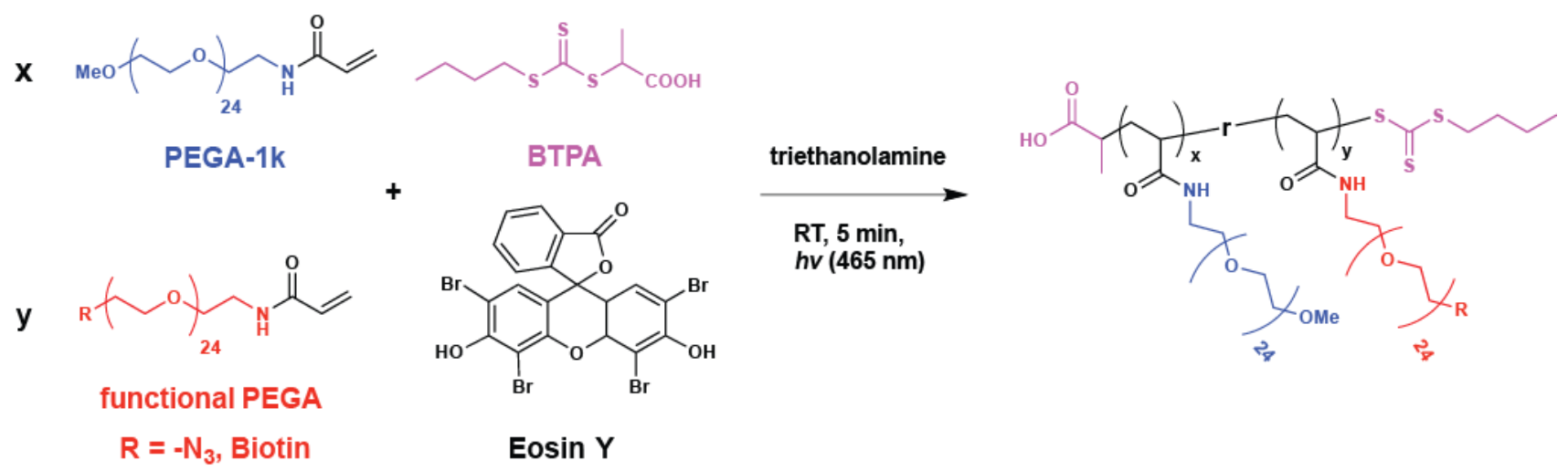

\begin{tabular}{|c|c|c|c|c|c|c|c|c|c|}
\hline Entry & $\begin{array}{l}{[\mathrm{M}]:[\mathrm{BTPA}]:[\text { Eosin } \mathrm{Y}]:} \\
\text { [triethanolamine] }\end{array}$ & $\begin{array}{l}M \\
(\approx y / x)\end{array}$ & $\begin{array}{l}\mathbf{R} \\
\text { group }\end{array}$ & $\begin{array}{l}\text { Catalyst } \\
\text { conc. }(\mu \mathrm{M})\end{array}$ & $\begin{array}{l}\text { With CTA- } \\
\text { modified } \\
\text { cells? }\end{array}$ & $\begin{array}{l}\text { Conv } \\
.(\%)^{a}\end{array}$ & $M_{\mathrm{n}, \mathrm{th}}{ }^{b}$ & $\begin{array}{l}M_{\mathrm{n}, \exp } \\
(\mathrm{GPC})\end{array}$ & $\mathrm{PDI}^{c}$ \\
\hline$\overline{1}$ & $80: 1: 0.01: 1$ & 0 & - & 62 & $\mathrm{~N}$ & 20 & 16,200 & 15,200 & 1.40 \\
\hline 2 & $80: 1.33: 0.015: 1$ & 0 & - & 94 & $\mathrm{~N}$ & 21 & 12,800 & 12,000 & 1.29 \\
\hline 3 & $80: 1.33: 0.015: 1$ & 0 & - & 94 & Yeast & 22 & 13,400 & 13,300 & 1.25 \\
\hline 4 & {$[72+8]: 1.33: 0.015: 1$} & $1 / 9$ & $\mathrm{~N}_{3}$ & 94 & Yeast & 35 & 21,200 & 17,400 & 1.36 \\
\hline 5 & {$[72+8]: 1.33: 0.015: 1$} & $1 / 9$ & biotin & 94 & Yeast & 19 & 11,600 & 11,300 & 1.24 \\
\hline 6 & {$[72+8]: 1: 0.01: 1$} & $1 / 9$ & biotin & 62 & Jurkat & N.D. ${ }^{d}$ & N.D. ${ }^{d}$ & 13,800 & 1.24 \\
\hline
\end{tabular}


a Monomer conversion determined by ${ }^{1} \mathrm{H}-\mathrm{NMR}$ spectroscopy.

$b$ Theoretical molecular weight calculated based on monomer conversion.

$c$ Molecular weight and polydispersity $\left(M_{\mathrm{w}} / M_{\mathrm{n}}\right)$ determined by GPC analysis (DMF with $0.1 \%$ LiBr used as eluent with PMMA standards).

$d$ N.D.: not determined. The time-zero mixture was not sampled to avoid introduction of oxygen in the degassed solution and minimize Jurkat cells' exposure to the reaction mixture.

To avoid injury to the cell, it is critical to develop a PET-RAFT process that affords fast kinetics, thereby limiting reaction time, while retaining control over polymerization. Previous work on visible light-mediated polymer encapsulation of live cells has shown that radical polymerization times of less than 10 minutes are essential to avoid a significant drop in cell viability, with high conversions also being undesirable due to loss of end group functionality. ${ }^{20-22,38}$ We therefore used equimolar CTA and cocatalyst for an accelerated reaction rate with the goal of $<30 \%$ conversion. ${ }^{37}$ Initial polymerization of methoxy-PEG acrylamide-1k (PEGA-1k) at a monomer: CTA: catalyst: co-catalyst ratio of 80: 1: 0.01: 1 (Table 1, Entry 1) under irradiation of a $465 \mathrm{~nm}$ LED light source $\left(5.0 \mathrm{~mW} / \mathrm{cm}^{2}\right)$ resulted in $20 \%$ monomer conversion in 5 minutes, with a modest degree of control over polymerization $\left(M_{\mathrm{n}}=15,200\right.$, $M_{\mathrm{w}} / M_{\mathrm{n}}=1.40$; Table 1, Entry 1). The light source was chosen to achieve rapid polymerization while avoiding cell injury. We reason that by increasing the ratio of CTA a higher degree of control over polymerization could be achieved. CTA acts as a radical deactivator according to the RAFT mechanism, ${ }^{39}$ and any increase in CTA concentration to increase the level of control must be offset kinetically by also increasing the catalyst concentration. Indeed, we found that increasing both CTA and catalyst loading enhanced control over polymerization while still maintaining a high reaction rate, yielding a polymer with $M_{\mathrm{n}}=12,400, M_{\mathrm{w}} / M_{\mathrm{n}}=1.29$ in 5 minutes (Table 1 , Entry 2 ).

Analysis of the kinetics under these improved conditions affords a linear relationship between $\ln \left([\mathrm{M}]_{0} /[\mathrm{M}]_{\mathrm{t}}\right) v s$. irradiation time up to 10 minutes, where $[\mathrm{M}]_{0}$ is the initial monomer concentration and $[\mathrm{M}]_{\mathrm{t}}$ is the monomer concentration at a given time (t) (Supplementary Information, Figure S2a). The evolution of the experimental $M_{\mathrm{n}}$, as measured by gel-permeation chromatography (GPC), with respect to 
monomer conversion also remains linear, with GPC analysis monitored by both reflective index (RI) and UV-Vis detectors showing closely matched molecular weight distributions, indicating well-preserved chain ends (Supplementary Information, Figures S2b, S2c and S3). ${ }^{27}$ It should be noted that we observed some deviation of experimental $M_{\mathrm{n}}$ from theoretical values, which is attributed to the difference in molecular structure of the branched polymer products and the linear PMMA standards used in the GPC studies. ${ }^{40}$ Overall, these results support that the polymerization is a living process with retention of the chain ends.

Under these optimized conditions, we then performed polymerization in the presence of live wildtype Saccharomyces cerevisiae (Baker's yeast, referred simply as yeast hereafter) cells. Yeast cells were initially cultured in yeast extract peptone dextrose (YPD), washed, resuspended in PBS buffer, and added to the reaction. After polymerization, yeast cell viability and capability to proliferate were determined by plating on agar and then colony counting after 48 hours. Specifically, we observed no detectable change in colony growth compared to untreated live yeast cells (Supplementary Information, Figure S4).

Table 2. Yeast cells modified with surface-initiated PET-RAFT. First, activated dibenzocyclooctyl (DBCO) reagents $\mathbf{1}$ or $\mathbf{2}$ are added to react with the surface amino groups of wild-type yeast cells, after which a strain-promoted cycloaddition (SPAAC) reaction with $\mathbf{3}$ is employed to conjugate CTA to the cell surface. Finally, PET-RAFT is used to produce yeast cells modified with synthetic polymers (Y1 Y5).

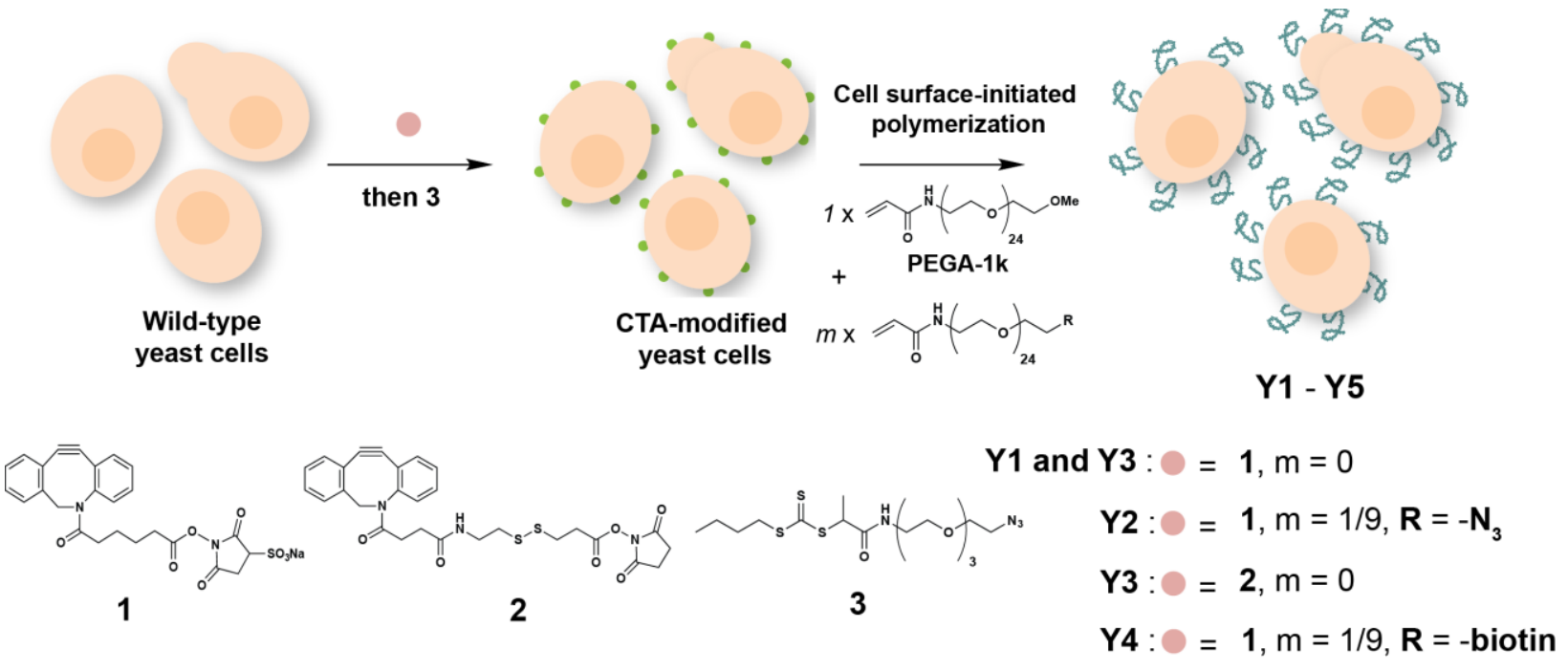




\begin{tabular}{llllll}
\hline $\begin{array}{l}\text { Polymer- } \\
\text { modified } \\
\text { yeast }\end{array}$ & Yeast strain & DBCO reagent & PEG acrylamides & R group & $\begin{array}{l}\text { [PEGA]: } \\
\text { [functional } \\
\text { PEGA] }\end{array}$ \\
\hline Y1 & WT $^{a}$ & $\mathbf{1}$ & PEGA-1k & - \\
Y2 & WT & 1 & PEGA-1k + PEGA-N $3-1 k$ & $-N_{3}$ & $9: 1$ \\
Y3 & GPCR ${ }^{+b}$ & 1 & PEGA-1k & - & - \\
Y4 & WT & 2 & PEGA-1k & - & - \\
Y5 & WT & $\mathbf{1}$ & PEGA-1k + PEGA-Bio-1k & -Biotin & $9: 1$ \\
\hline
\end{tabular}

a WT: wild-type Saccharomyces cerevisiae

$b \quad$ GPCR $^{+}$: Saccharomyces cerevisiae strain BJ5465 expressing plasma membrane-associated human A2aAdenosine receptors (a $\mathrm{G}$ protein-coupled receptor, or GPCR)

\section{Characterization of cell surface-initiated polymerization}

Having demonstrated the compatibility of live yeast cells with PET-RAFT, we investigated direct initiation of polymer growth from cell surfaces. One strategy for the formation of grafting-from polymers involves the conjugation of initiating CTA groups to the surface of yeast cells. A two-step approach was therefore developed involving initial amidation followed by copper-free, strain-promoted azide-alkyne cycloaddition (SPAAC, or copper-free click chemistry) to conjugate the CTA to the cell surface (Table 2). We avoided directly activating the carboxylic acid group of BTPA in the form of $N$-hydroxysuccinimide (NHS) ester in the coupling reaction, instead choosing to initially couple cell surface amino groups to the dibenzocyclooctyl (DBCO)-based activated ester 1, allowing the introduction of azide-reactive cyclooctyne groups on the cell surface. ${ }^{41,42}$ This is an important consideration as the negatively charged sulfo-NHS moiety of $\mathbf{1}$ prevents it from passing across the cell membrane leading to cytotoxicity. The second step involves reacting azido-containing BTPA derivative $\mathbf{3}$ with cell surface-conjugated DBCO groups through SPAAC. We investigated labeling efficiency by coupling a fluorescent dye, Alexa Fluor 647 azide, to the cell surface DBCO groups, and observed highly specific conjugation to the cell surface based on the intense and uniform fluorescence from the yeast cell surface. It should be noted that no fluorescence was observed inside the cells (Supplementary Information, Figure S5).

To confirm cell viability after CTA modification, yeast cells were treated with fluorescein diacetate (FDA), a well-established yeast viability assay that indicates esterase activity in cells..$^{5}$ The 
signal from this assay can be measured with fluorescence microscopy or flow cytometry, with the latter providing quantitative measurement of the fraction of the live cells in the total population. We observed a high viable fraction (>95\%) in the analyzed population of 10,000 yeast cells modified by CTA, (Supplementary Information, Figure S6). The proliferation of these cells was further confirmed by agar plating assays as well as by monitoring cell proliferation in growth media (Figure 2e and Supplementary Information, Figure S7).

Cell surface-initiated PET-RAFT was then performed with the CTA-modified yeast cells (Table 2). The reaction was conducted in PBS buffer ( $\mathrm{pH}$ 7.4) with Eosin Y/triethanolamine as the catalyst/cocatalyst and PEGA-1k as the monomer using a $465 \mathrm{~nm}$ LED light source $\left(5.0 \mathrm{~mW} / \mathrm{cm}^{2}\right)$ to give the desired polymer-grafted yeast cells Y1. Similar to polymer brush formation on abiotic surfaces using traditional RAFT chemistry, we found that addition of sacrificial CTA to the polymerization system was required to maintain control. ${ }^{43,44}$ In the presence of sacrificial CTA, polymers were initiated from both BTPA in solution and cell surface-attached CTA, with GPC characterization of the soluble polymer product revealing good control over polymerization $\left(M_{\mathrm{n}}=13,300, M_{\mathrm{w}} / M_{\mathrm{n}}=1.25\right.$; Table 1 , Entry 3$)$. To demonstrate the introduction of functional polymers to the cell surface, the same cell surface-initiated polymerization was repeated with a 9:1 mixture of PEGA-1k and $\omega$-azido PEG acrylamide, $M_{\mathrm{w}}=1 \mathrm{kDa}$ (PEGA-N $3-1 \mathrm{k}$ ), yielding azide-modified yeast cells, Y2. GPC analysis of the solution copolymer shows a slight increase in polydispersity compared to the homopolymer $\left(M_{\mathrm{n}}=17,400, M_{\mathrm{w}} / M_{\mathrm{n}}=1.36\right.$; Table 1 , Entry 4 and Supplementary Information, Figure S8a). ${ }^{45-47}$ Having grown functional polymer brushes on cell surfaces it was important to demonstrate the retention of reactivity for the azido groups. Modified yeast cells Y2 were therefore separated from the reaction mixture via centrifugation, thoroughly washed with PBS, and subsequently functionalized with Alexa Fluor 647 DIBO, a derivative of Alexa Fluor 647 that reacts with the azido groups of the polymers through SPAAC.

Confocal microscopy of the fluorescently labeled Y2 showed strong Alexa Fluor 647 fluorescence only at the cell surface (Figure 2a and c), indicating little or no polymer growth inside the 
cells with the presence of fluorescence also confirming the reactivity of azido groups introduced via polymer surface-grafting of the yeast cells. Control experiments clearly demonstrated the absence of fluorescence for CTA-modified cells that did not undergo cell surface-initiated polymerization, or those grafted with only non-functionalized PEGA-1k monomer (Y1) (Supplementary Information, Figure S9 and S10). Taken together, these results clearly demonstrate the utility of our process for engineering the surface of live yeast cells through the formation of reactive polymers and post-polymerization functionalization.
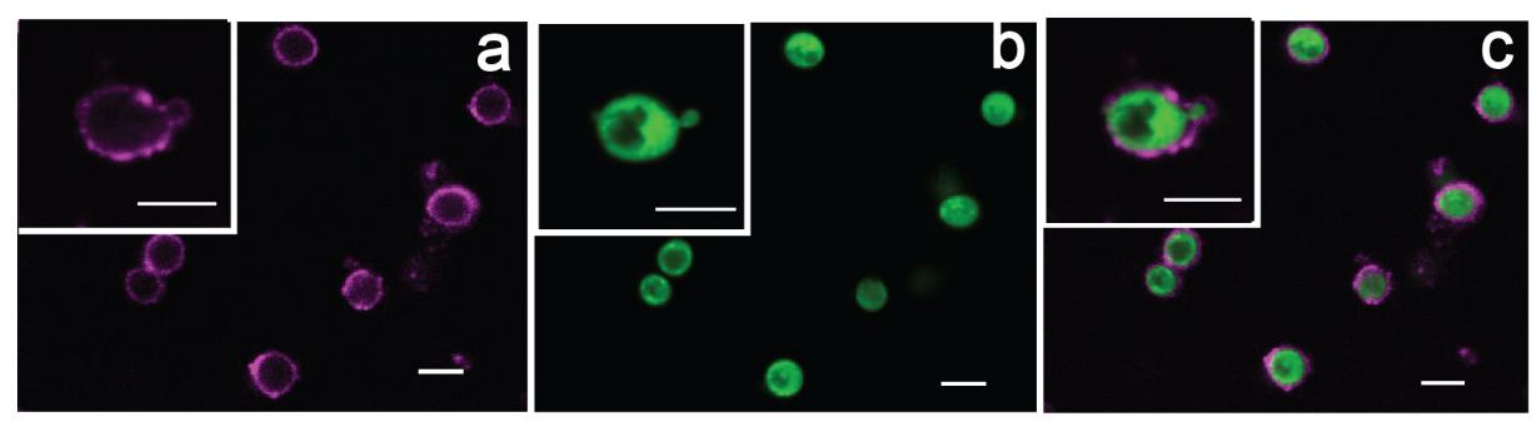

d
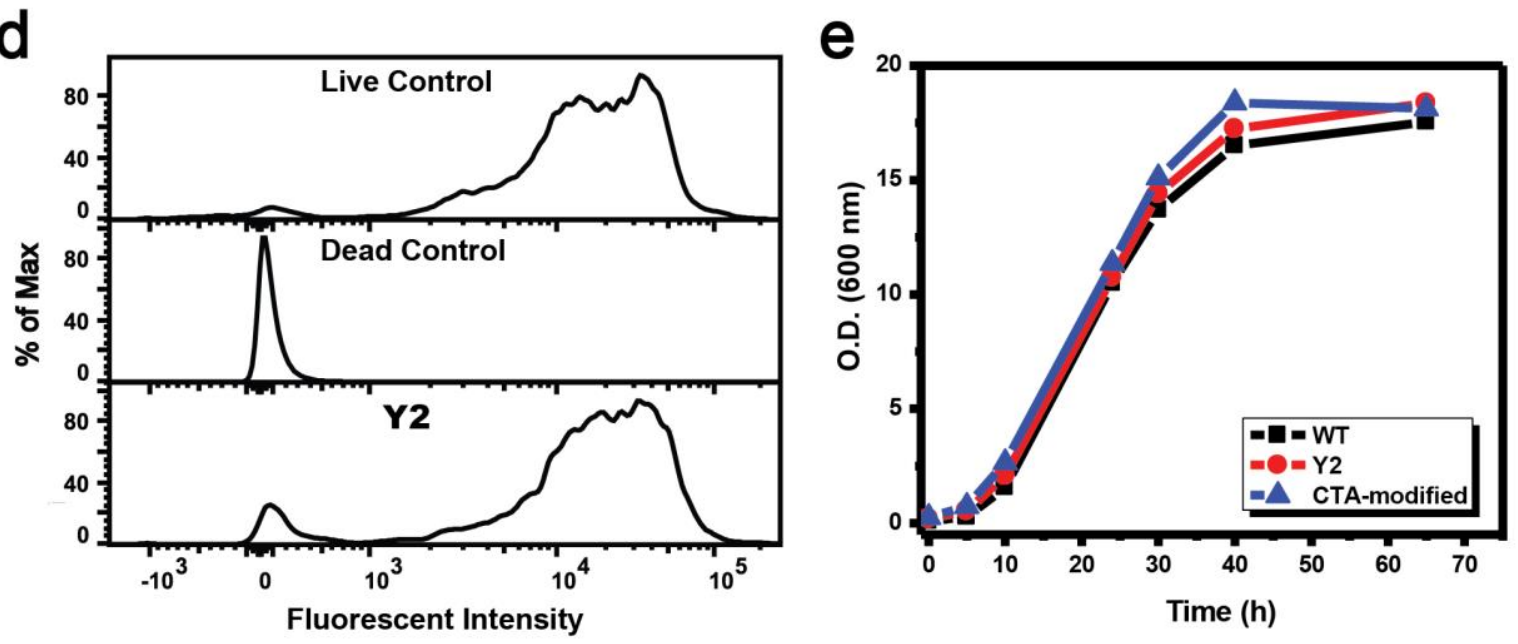

Figure 2. Characterizations of polymer coating and viability of the modified yeast cells. (a-c) Confocal fluorescent microscopy shows fluorescent labeling of treated yeast cells, with insets showing a single polymer-modified yeast cell. (a) Polymers on the surface of Y2 were specifically labeled with Alexa Fluor 647 DIBO, demonstrating that modification exclusively occurs at the cell surface. The residual signal in the background is likely caused by the polymers in solution phase that were not completely removed by the washing steps. (b) Fluorescein diacetate (FDA) treatment confirms the maintenance of cell viability. (c) Merged image data from the channels shown in (a) and (b). All scale bars are $5 \mu \mathrm{m}$. (d) We used quantitative flow cytometry to measure the cell population that can convert FDA into fluorescently active fluorescein. $90 \%$ of Y2 were viable by this metric, comparable with the wild-type control. (e) Yeast cell growth curve of wild-type (WT), CTA and polymer modified yeast cells. Optical density at $600 \mathrm{~nm}$ (O.D.600) indicates the cell density of the suspension. 


\section{Viability and proliferation of polymer-modified yeast cells}

A prime objective of this work is to develop strategies for cell surface modification while retaining high viability. To confirm that the polymer-modified cells are viable with retention of their capability to proliferate, polymer-modified yeast cells Y2, were treated with FDA and subsequently imaged by confocal fluorescence microscopy. Strong green fluorescence was observed in the cytoplasm, indicating the presence of functional esterases (Figure $2 b$ ) while flow cytometry additionally revealing > $90 \%$ viability (analysis was of a population of $\sim 10,000$ cells obtained from a suspension of polymermodified yeast cells) (Figure 2d). Importantly, the growth curve of Y2 re-cultured in YPD media showed no difference in comparison to wild-type cells, with both reaching exponential stage after 10 hours and saturation stage after 40 hours (Figure 2e). This is in direct contrast to prior work on yeast cell encapsulation, where the surrounding crosslinked matrix significantly altered the cell cycle (Supplementary Information, Figure S5)..$^{5,48}$

We hypothesize that the mild grafting-from polymer modification employed here does not alter yeast cell wall properties, enabling cells to maintain their regular function and metabolism. Indeed, after 4 hours of re-culturing in growth media, imaging of Alexa Fluor 647 DIBO-labeled Y2 showed that the labeled polymers were distributed on the surfaces of both parent cells and newly formed daughter cells (Supplementary Information, Figure S11). In certain cells, the polymers were also observed to be internalized along with the cell walls to which they were attached, and replaced by newly formed nonfluorescent cell walls. Significantly, cell wall internalization and re-distribution of parent cell wall fragments to progeny cells are two characteristic events in yeast cell wall metabolism, ${ }^{49-51}$ and the observation that both processes occur normally in polymer-modified cells is strongly indicative of regular 
cell wall function and metabolism. In addition, when treated with lyticase, a digestive enzyme that can degrade the yeast cell wall, modified yeast cells did not exhibit altered degradation kinetics compared to wild-type yeast, adding further evidence that polymer modification does not affect cell wall properties and suggests that cell surface glycans, substrates of lyticase, are not affected by the grafted polymers (Supplementary Information, Figure S12). In contrast, yeast cell surfaces encapsulated by a crosslinked polymer matrix in prior work have shown resistance against lyticase-mediated cell wall degradation. ${ }^{5,48}$ We attribute the lack of protection against cell wall degradation of the polymer-modified yeast in this work to the heterogeneity of the cell surface, as the covalent modifications of CTA on the amino groups of cell surface proteins, and thereby the polymers grown from the CTAs, do not cover the entire cell surface. As a result, the large areas of glycans on the cell surface were not modified, and thus were susceptible to lyticase degradation. Additional confirmation of the cytocompatible nature of this approach was obtained by examining cell surface protein function. Polymerization was therefore conducted from a yeast strain that expresses plasma membrane-localized human adenosine A2a receptor (a G proteincoupled receptor, or GPCR), yielding polymer-modified $\mathrm{GPCR}^{+}$yeast cells, Y3. ${ }^{52}$ Comparison of the affinity of FITC-APEC, a ligand for GPCR, shows very similar behavior for the polymer-grafted cells, Y3 (dissociation constant, $K_{\mathrm{d}}=16.1 \mu \mathrm{M}$ ), when compared to the non-polymer-modified GPCRexpressing yeast cells $\left(K_{\mathrm{d}}=10.2 \mu \mathrm{M}\right)$. This result clearly shows that the cell surface protein receptors remain functional after cell surface-initiated polymerization (Supplementary Information, Figure S13). These two features of our process - unaltered cell surface properties and functional cell surface proteins will enable our engineered cells for applications that require unhindered mass transport, signal transduction, and other biological functions mediated by the native structures at the cell surface. 

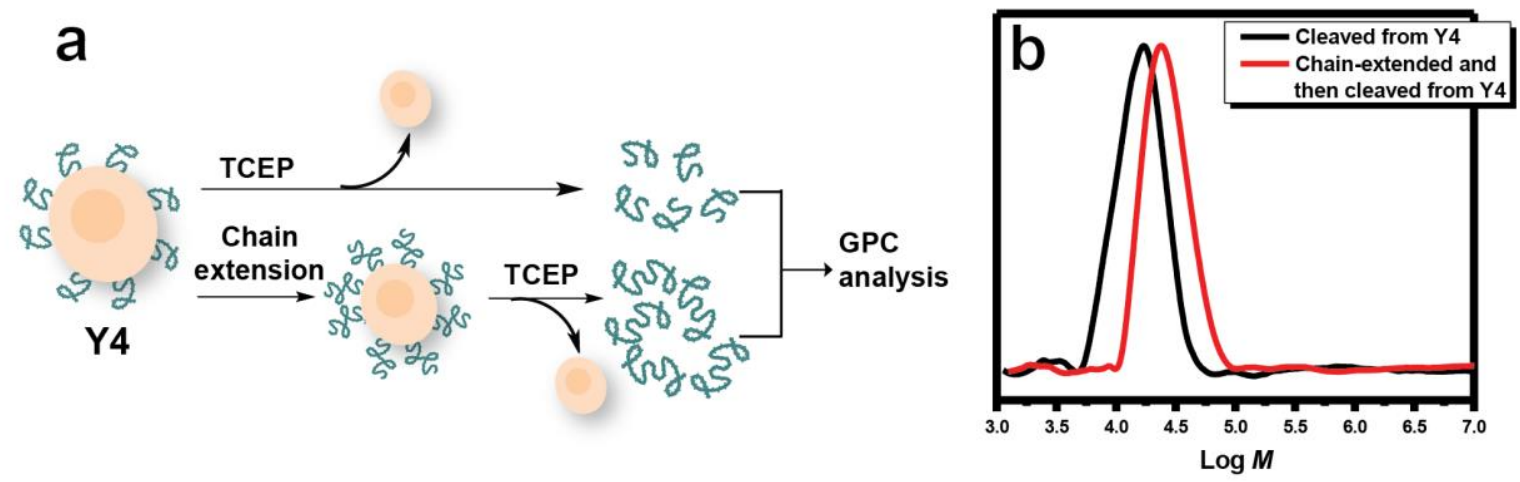

Figure 3. Polymer cleavage and in situ chain extension confirmed well-defined covalent polymers with preserved chain end formed on the cell surface. (a) Scheme of chain extension of Y4 and subsequent polymer cleavage by TCEP treatment. (b) GPC analysis of the polymers directly cleaved from Y4 (black line, $M_{\mathrm{n}}=11,900, M_{\mathrm{w}} / M_{\mathrm{n}}=1.19$ ) and the polymers cleaved after chain extension of Y4 (red line, $\left.M_{\mathrm{n}}=20,200, M_{\mathrm{w}} / M_{\mathrm{n}}=1.22\right)$.

\section{Confirmation of polymerization control and chain extension on cell surface}

In order to unambiguously confirm that covalent polymers were formed on the cell surface, we modified the prior strategy to allow cleavage of the graft polymers from the cell surface. Yeast cells were therefore functionalized through a cleavable disulfide linker and as shown in Table 2, the customized disulfide-containing activated ester 2 was used to introduce the DBCO group onto the surface of live yeast cells, followed by reaction with $\mathbf{3}$ to attach the CTA moiety. After cell surface-initiated polymerization, polymer-grafted yeast cells, Y4, were obtained containing the desired disulfide linker. Treatment with tris(2-carboxyethyl)phosphine (TCEP) specifically reduces the disulfide linker leading to cleavage of the grafted polymers from the cell surface. GPC analysis of these chains revealed similar molecular weight characteristics $\left(M_{\mathrm{n}}=11,900, M_{\mathrm{w}} / M_{\mathrm{n}}=1.19\right)$ to polymers formed in solution (Table 1 , Entry 2) (Figure 3). To further illustrate chain-end group fidelity and demonstrate the utility of the cell surface-initiated CRP process, re-initiation of polymer growth from Y4 was then examined. Significantly, chain extension of Y4 with a second poly(PEGA-1k) block followed by TCEP treatment and GPC analysis showed a complete shift to the higher molecular weight end while still maintaining low polydispersity $\left(M_{\mathrm{n}}=20,200, M_{\mathrm{w}} / M_{\mathrm{n}}=1.22\right)$ (Figure $\left.3 \mathrm{~b}\right)$. This ability to incorporate cleavable linkers and 
perform chain extension highlights the high degree of control over polymerization with cell surfaceinitiated PET-RAFT and also points towards potential applications in generating more complex, multiblock polymer architectures for cell surface engineering.
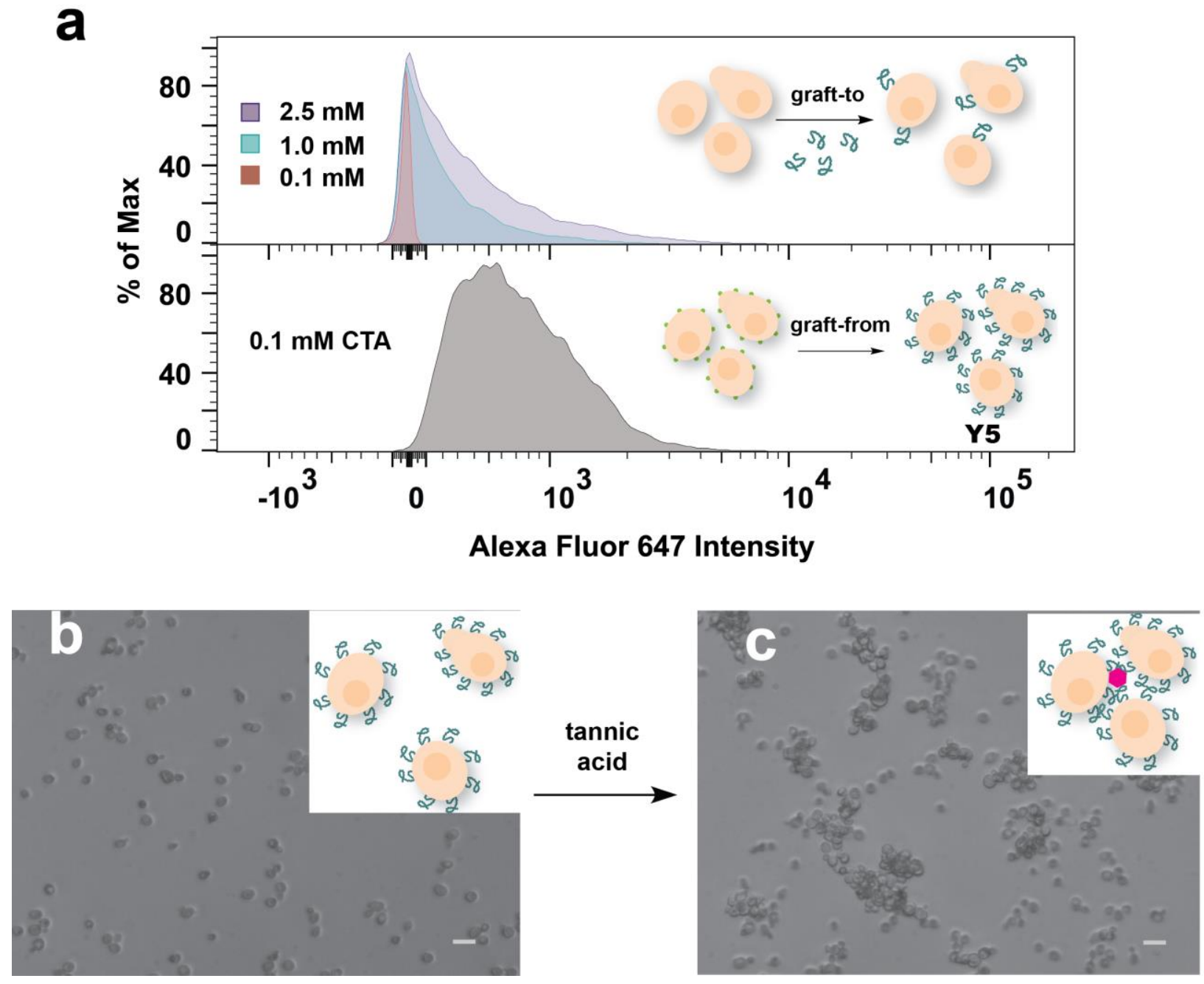

Figure 4. Utility of cell surface-initiated polymerization on yeast cells. (a) Our grafting-from approach exhibited significantly enhanced polymer grafting compared to the grafting-to approach. We used Alexa Fluor 647-conjugated streptavidin to compare polymer grafting onto live yeast cells via (top) biotin-PEG-NHS-20k at 0.1, 1.0, and $2.5 \mathrm{mM}$ concentrations with a 'grafting-to' approach or (bottom) $0.1 \mathrm{mM}$ of $\mathbf{3}$ using our PET-RAFT-based 'graft-from' approach (Y5). (b) and (c) Manipulation of cellular phenotype by the grafted polymers. Tannic acid (TA), which can bind to PEG through hydrogen bonding interactions, was introduced to mediate aggregation of polymer-modified yeast cells. Brightfield microscope images show Y1 (a) before and (b) after TA treatment. Scale bars are $5 \mu \mathrm{m}$. 
For traditional surfaces, one unique advantage of surface-initiated polymerization compared to conventional grafting-to approaches is the ability to form polymer brushes with high areal chain density. To investigate whether cell surface-initiated PET-RAFT also leads to improved grafting on cell surfaces even with the increased steric repulsion from the dense native macromolecular structures (e.g. proteins and polysaccharides), cell surface-initiated polymerization was conducted from CTA-modified yeast cells using a 9:1 monomer mixture of PEGA-1k and $\omega$-biotin-PEG acrylamide, $M_{\mathrm{w}}=1 \mathrm{kDa}$ (PEGA-bio-1k). This affords the biotin-grafted cells, Y5, with GPC characterization of the soluble polymer chains showing control over the polymerization $\left(M_{\mathrm{n}}=11,300, M_{\mathrm{w}} / M_{\mathrm{n}}=1.24\right.$, Table 1 , Entry 5 , and Supplementary Information, Figure S8b). This correlates to, on average, one biotin group per polymer chain. Quantitative flow cytometry analysis of Y5 after binding with Alexa Fluor 647-conjugated streptavidin revealed robust fluorescence (Figure 4a). In contrast, significantly lower fluorescence and associated polymer grafting was observed for yeast cells functionalized through a grafting-to strategy with biotin-PEG-NHS, 20 kDa (Biotin-PEG-NHS-20k) followed by labeling with Alexa Fluor 647conjugated streptavidin. At the same molar concentration, (0.1 $\mathrm{mM}$ of biotin-PEG-NHS-20k), cells modified showed very little signal and even at 10- and 25-fold higher concentrations (1.0 and $2.5 \mathrm{mM}$, respectively), the grafting-to approach still resulted in minimal fluorescence (Figure 4a). This large difference in grafting was also confirmed by confocal fluorescence microscopy, with a visibly stronger fluorescence for cells modified by the grafting-from PET-RAFT approach (Supplementary Information, Figure S14).

\section{Controlling cell aggregation and assembly}

An important goal of cell surface engineering is to control cell-cell interactions. To this end, we examined the influence of grafting chemistry on cellular aggregation and assembly for polymer modified yeast cells. Specifically, tannic acid (TA), a compound known to interact with PEG polymers through hydrogen bonding interactions in aqueous solution, ${ }^{53-55}$ was added to a suspension of polymer-modified yeast cells, Y1, resulting in a final concentration of $5 \mathrm{mM}$. Little or no cell aggregation was observed for 
the modified cells prior to the addition of TA (Figure 4b), but after incubation with TA for 1 hour under mild shaking, we observed considerable aggregation of the polymer-grafted cells (Figure 4c). No aggregation was apparent in wild-type yeast cell suspensions after addition of TA (Supplementary Information, Figure S15a, b). Importantly, compared to Y1, biotin-PEG-NHS-20k-modified yeast cells generated by the grafting-to approach showed significantly less aggregation in the presence of TA, with only minor aggregation observed for cells grafted with $2.5 \mathrm{mM}$ biotin-PEG-NHS-20k, a 25-fold higher concentration than that used for the modification of CTA 3 (Supplementary Information, Figure S15c-e). Notably, after TA treatment and cell aggregation, Y1 still exhibited robust viability as measured with the FDA assay (Supplementary Information, Figure S16). These results clearly demonstrate that cytocompatible polymer coatings can be used to actively moderate cellular aggregation by the interaction between TA and surface grafted poly(PEGA-1k). 

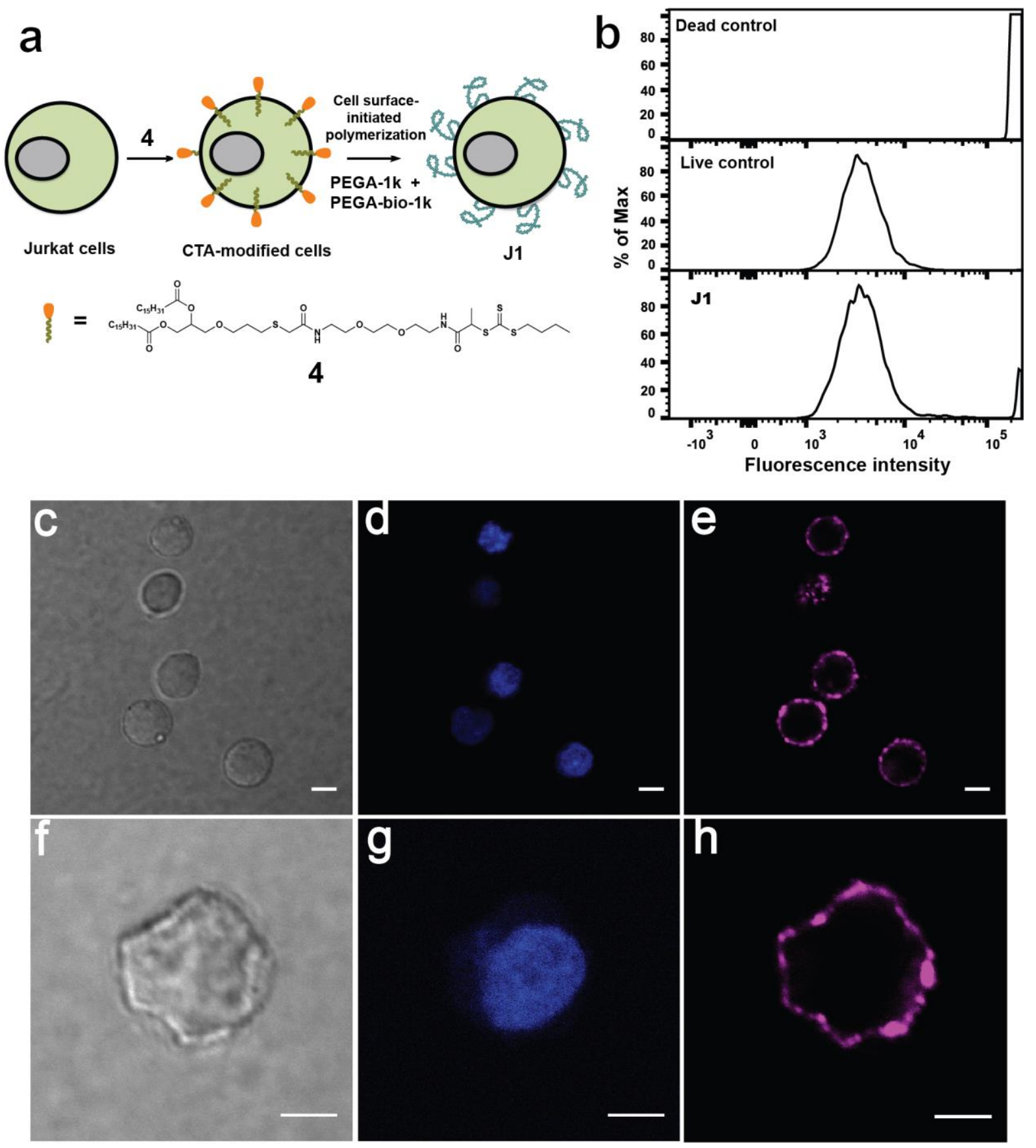

Figure 5. Cell surface-initiated polymerization on Jurkat cells. (a) Modification of cell surface using CTA-Lipid and subsequent cell surface-initiated polymerization. A biotinylated monomer was incorporated to enable labeling with streptavidin after polymerization. (b) Cell viability after polymerization. We employed a flow cytometry-based cell membrane integrity assay to determine the percentage of viable cells in the total population. A reactive dye is non-permeable to the intact cell membrane while could stain membrane-damaged dead cells, causing high fluorescence for dead cells and low signal for live cells. A live control and a dead control were assayed in the same time as the test sample. Flow cytometry gives $90 \%$ viability after polymerization. (c - h) Confocal microscope images of Jurkat cells modified by cell surface-initiated polymers. (c - e) Image shows multiple cells. (f - h) Zoomed-in image showing a single modified cell. (c) and (f) Transmission image; (d) and (g) cell nucleus stained by DAPI; (e) and (h) polymer labeled by AF647-streptavidin. Scale bars are 5 $\mu \mathrm{m}$. 


\section{Mammalian cell surface-initiated polymerization}

Next, we investigated the cytocompatibility of our CRP process for modifying the surfaces of live mammalian cells using human Jurkat cells as a model. Compared to yeast, engineering mammalian cells is more challenging. For example, the lack of cell wall renders mammalian cells both mechanically and chemically more sensitive to environmental stress. Indeed, our initial attempt at covalently modifying Jurkat cell surface using the same procedure for yeast cells, followed by cell surface-initiated polymerization, resulted in poor cell viability (Supplementary Information, Figure S17). We reasoned that covalent modification leads to excessive cellular stress and switched to an alternative strategy for anchoring CTA groups to the cell surface using lipidomimetic compounds. ${ }^{11,56}$ We therefore designed the lipid analog 4 bearing a CTA head group, a hydrophilic spacer, and a non-charged DPPE-mimicking C16 tail for non-covalent modification of the Jurkat cell membrane (Figure 5a).

The Jurkat cells were therefore treated with 4 at $40 \mu \mathrm{M}$ in PBS buffer for 30 min at $4{ }^{\circ} \mathrm{C}$, followed by cell surface-initiated polymerization using a reaction mixture containing the same $\omega$-biotinPEG acrylamide, $M_{\mathrm{w}}=1 \mathrm{kDa}$ (PEGA-bio-1k) as used above for the yeast cells. The catalyst concentration was also lowered in these polymerizations with mammalian cells to further reduce the chemical stress from the radical polymerization with the CTA concentration also correspondingly reduced to maintain polymerization rate. Significantly, polymerization from the CTA-anchored cells using a 9:1 monomer mixture of PEGA-1k and PEGA-bio-1k at a monomer: CTA: catalyst: co-catalyst ratio of 80: 1: 0.01: 1 (Table 1, Entry 6) resulted in control over the polymerization (soluble (non-anchored) polymers showed $\left(M_{\mathrm{n}}=13,900\right.$ and $M_{\mathrm{w}} / M_{\mathrm{n}}=1.24$, see Table 1 , Entry 6 , and Supplementary Information, Figure S8c). The polymer-modified Jurkat cells, J1, were then separated from the reaction mixture via centrifugation, thoroughly washed with PBS, and subsequently labeled with Alexa Fluor 647-conjugated Streptavidin. Confocal microscopy of the fluorescently labeled $\mathbf{J 1}$ revealed a strong Alexa Fluor 647 signal only at the

cell surface (Figure $5 \mathrm{c}-\mathrm{h}$ ) and control experiments with non-functionalized PEGA-1k monomer only (Supplementary Information, Figure S18) or lacking the CTA-bearing lipid analog 4 (Supplementary 
Information, Figure S19), showed minimal fluorescence. Taken together, these results confirmed the formation of functional polymers on the surface of mammalian cells.

Next, we used two different assays to confirm that our polymer-modified Jurkat cells were viable. First, we used a cell membrane integrity assay wherein our polymer-modified $\mathbf{J 1}$ cells were treated with a fluorescent reactive dye that do not stain live cells (with intact membranes) but strongly stain dead cells (with compromised membranes). Through flow cytometry, we observed that approximately $90 \%$ of $\mathbf{J 1}$ cells (in a population of $\sim 1,000$ cells) are viable with intact membranes (Figure 5 b). To unambiguously confirm that $\mathbf{J 1}$ cells not only possessed intact membranes, but were also metabolically active, we employed a second Calcein-AM (green)/eithidium homodimer (red)-based, Live/Dead assay to show that

$\sim 90 \%$ of the cells were metabolically active and exhibited robust green fluorescence (Supplementary Information, Figure S20). Taken together, the two viability assays confirm that approximately $90 \%$ of our polymer-modified Jurkat cells are viable with intact cell membranes and active metabolism.

\section{Conclusion}

We report the first cytocompatible, visible light-mediated strategy for generating structurally defined synthetic polymers on live yeast and mammalian cell surfaces. Polymerization initiating CTA groups were introduced on the cell surface using either a covalent (yeast) or a non-covalent insertion strategy (mammalian). Well-defined grafting chains could be directly initiated from the cell surface without compromising cell viability When compared to traditional approaches, the increased efficiency of polymer grafting in these systems enabled the cellular phenotype to be manipulated by deliberately inducing aggregation and assembly in the presence of tannic acid. Given that these methods could be readily expanded to graft a wide range of functional polymers onto cell surfaces, we believe it offers the exciting potential to a number of potential applications, such as generating high-density glycopolymers 
with defined carbohydrate side-chain structures to rewire signaling pathways, or using light to control spatial and temporal distributions of cell surface-grafted polymers for the manipulation of cell-cell interactions and their underlying cellular processes.

\section{Methods}

For complete experimental methods see the Supplementary Information.

\section{Yeast culturing, CTA conjugation to the cell surface and cell surface-initiated polymerization}

The following procedure describes typical conditions for surface-initiated polymerizations at the ratio of PEGA-1k: BTPA: Eosin Y: triethanolamine equal to 80: 1.33: 0.015: 1, used to prepare yeast cells modified with poly(PEGA-1k) homopolymer Y1. Other monomer compositions typically followed the same procedure, but with different ratios of monomers while keeping the total molar concentration of monomers constant. Unless otherwise stated, the centrifugation steps in the following procedure were performed at $1,500 \times g .1 \times \mathrm{PBS}$ buffer was at $\mathrm{pH} 7.4$.

(1) Yeast cells from a single colony on an agar plate were inoculated in $5 \mathrm{~mL}$ of autoclaved yeast extract peptone dextrose (YPD) media in a culture tube. The culture tube was then incubated at $30{ }^{\circ} \mathrm{C}$ under constant shaking at $300 \mathrm{rpm}$ for $16 \mathrm{~h}$. The yeast cells were then pelleted by centrifugation, washed three times with $5 \mathrm{~mL}$ PBS, and resuspended in $2 \mathrm{~mL}$ PBS.

(2) $0.5 \mathrm{~mL}$ of the yeast cell suspension prepared in the last step was combined with $25 \mu \mathrm{L}$ of freshly prepared $2 \mathrm{mg} / \mathrm{mL}$ solution of 1 in PBS and incubated for $60 \mathrm{~min}$ on ice. After incubation, we centrifuged and washed twice with $1 \mathrm{~mL} 50 \mathrm{mM}$ Tris buffer ( $\mathrm{pH} \mathrm{8.0)}$ and once with PBS before resuspending in $0.5 \mathrm{~mL}$ PBS.

(3) This suspension of DBCO-modified yeast cells was combined with $0.5 \mu \mathrm{L}$ of $100 \mathrm{mM}$ stock solution of $\mathbf{3}$ in acetonitrile and incubated in darkness on ice for 1 hour. For experiments in which DBCO-modified cells were labeled with Alexa Fluor 647 azide, we used $2 \mu \mathrm{L}$ of $5 \mathrm{mM}$ Alexa Fluor 647 azide instead of $\mathbf{3}$. We centrifuged the yeast cell suspension, discarding the supernatant. We resuspended the yeast cell pellet in $0.5 \mathrm{~mL}$ of $1 \mathrm{mM}$ 6-azido-6-deoxy-D-glucose solution in PBS and incubated on ice for 15 min. After pelleting the cells by centrifugation and washing three times with $1 \mathrm{~mL}$ PBS, we resuspended the cells in $100 \mu \mathrm{L}$ PBS.

(4) Cell surface-initiated polymerization was conducted in $\mathrm{pH} 7.4 \mathrm{PBS}$ in a $1.5 \mathrm{~mL}$ transparent glass vessel equipped with a rubber septum. BTPA $(0.5 \mathrm{mg}, 2.08 \mu \mathrm{mol})$ was aliquoted into the glass vial from a pre-dissolved stock solution in acetonitrile and evaporated under vacuum to dryness. We sequentially added $150 \mu \mathrm{L}$ PBS, PEGA-1k (125 mg, $0.125 \mathrm{mmol}), 20.6 \mu \mathrm{L} 1 \% \mathrm{v} / \mathrm{v}$ triethanolamine solution in PBS, $30.3 \mu \mathrm{L}$ of $0.5 \mathrm{mg} / \mathrm{mL}$ Eosin Y solution in PBS, and $100 \mu \mathrm{L}$ of CTA-modified yeast cell suspension from the last step. $25 \mu \mathrm{L}$ of this mixture was withdrawn, centrifuged, and the supernatant was added into $1 \mathrm{~mL} \mathrm{D}_{2} \mathrm{O}$ as the time-zero reference for monomer conversion analysis by NMR. A $27 \mathrm{G}, 1 / 2$ " needle was connected to the argon (Ar) 
source and inserted through the rubber septum to purge Ar, and another $27 \mathrm{G}, 1 / 2$ " needle was inserted through the septum to vent. We purged Ar through the reaction for $10 \mathrm{~min}$ before removing the needles. The reaction mixture was then allowed to polymerize in a dark chamber under irradiation for $5 \mathrm{~min}$ under constant shaking at $250 \mathrm{rpm}$. Immediately after the light source was turned off, $25 \mu \mathrm{L}$ of the reaction mixture was withdrawn, centrifuged, and the supernatant was added into $1 \mathrm{~mL} \mathrm{D}_{2} \mathrm{O}$ as the post-reaction sample for monomer conversion analysis by NMR. The integral difference of the acryl protons between the post-reaction sample and the time-zero reference was used to calculate monomer conversion. The rest of the mixture was then centrifuged, and the supernatant was added into a dialysis tube ( $\mathrm{MWCO}=3.5 \mathrm{k}$ ) and dialyzed against water for $48 \mathrm{~h}$. The dialyzed product was lyophilized and redissolved in chloroform for GPC analysis. The yeast cell pellet post-centrifugation was washed five times by $0.5 \mathrm{~mL}$ PBS, and resuspended in $0.5 \mathrm{~mL}$ PBS.

\section{Jurkat cell culturing, CTA anchoring to the cell surface, cell surface-initiated polymerization, and} polymer labeling by Alexa Fluor 647-conjugated streptavidin

Unless otherwise stated, the centrifugation steps in the following procedure were performed at $300 \times g$. $1 \times$ PBS buffer was at $\mathrm{pH} 7.4$.

(1) Human Jurkat cell line was obtained from ATCC and maintained in a humidified $\mathrm{CO}_{2}$ incubator at $37{ }^{\circ} \mathrm{C}$. The cells were cultured in RPMI-1640 medium (Thermo Scientific) supplemented with $10 \%$ fetal bovine serum (FBS; Thermo Scientific) and $1 \%$ penicillin/streptomycin (Thermo Scientific). Prior to the lipid modification, Jurkat cells $\left(2.5 \times 10^{6}\right.$ cells $)$ were collected by centrifugation for $10 \mathrm{~min}$ and washed three times with cold PBS. Next, cells were resuspended in $0.5 \mathrm{~mL}$ of cold PBS for the lipid modification step.

(2) Jurkat cells prepared in the last step were combined with $20 \mu \mathrm{L}$ of freshly prepared $1 \mathrm{mM}$ solution of 4 in DMSO and incubated for $30 \mathrm{~min}$ on ice. After incubation, we centrifuged and washed three times with $1 \mathrm{~mL}$ ice cold PBS before resuspending in $0.1 \mathrm{~mL}$ PBS.

(3) Cell surface-initiated polymerization was conducted in $\mathrm{pH} 7.4 \mathrm{PBS}$ in a $1.5 \mathrm{~mL}$ transparent glass vessel equipped with a rubber septum. BTPA $(0.375 \mathrm{mg}, 1.57 \mu \mathrm{mol})$ was aliquoted into the glass vial from a pre-dissolved stock solution in acetonitrile and evaporated under vacuum to dryness. We sequentially added $150 \mu \mathrm{L}$ PBS, PEGA-1k (112.5 mg, $0.1125 \mathrm{mmol})$, PEGA-bio-1k (12.5 mg, $0.0125 \mathrm{mmol}), 20.6 \mu \mathrm{L} 1 \% \mathrm{v} / \mathrm{v}$ triethanolamine solution in PBS, and $20.2 \mu \mathrm{L}$ of $0.5 \mathrm{mg} / \mathrm{mL}$ Eosin Y solution in PBS. A $27 \mathrm{G}, 1 / 2$ " needle was connected to the nitrogen $\left(\mathrm{N}_{2}\right)$ source and inserted through the rubber septum to purge $\mathrm{N}_{2}$, and another $27 \mathrm{G}, 1 / 2$ " needle was inserted through the septum to vent. We purged $\mathrm{N}_{2}$ through the reaction for $5 \mathrm{~min}$, added $100 \mu \mathrm{L}$ of CTA-anchored Jurkat cell suspension from the last step into the vial, reseal the vial, and kept $\mathrm{N}_{2}$ to flow thorough the space above the cell suspension in the vial for 5 more minutes before removing the needles. The reaction mixture was then allowed to polymerize in a dark chamber under irradiation for 5 min under constant shaking at $250 \mathrm{rpm}$. Immediately after the light source was turned off, the mixture was added $0.9 \mathrm{~mL}$ PBS and then centrifuged, and the supernatant was added into a dialysis tube $(\mathrm{MWCO}=3.5 \mathrm{k}$ ) and dialyzed against water for $48 \mathrm{~h}$. The dialyzed product was lyophilized and redissolved in chloroform for GPC analysis. The Jurkat cell pellet postcentrifugation was washed four times by $0.5 \mathrm{~mL}$ PBS, and resuspended in $0.5 \mathrm{~mL}$ PBS. 
(4) Polymer-modified cells from last step were added AF647-Streptavidin to the final concentration of $10 \mu \mathrm{g} / \mathrm{mL}$. Incubate on ice for $30 \mathrm{~min}$. The labeled cells were washed twice by $0.5 \mathrm{~mL}$ PBS and were subsequently characterized by viability assays and confocal fluorescent microscopy studies.

\section{Acknowledgements}

The authors thank the financial support of DARPA (N66001-14-2-4055), ARO (W911QY-15-C-0026) and the Garland Initiative. We gratefully acknowledge Charles Haitjema for help in yeast culturing, Rachel Behrens for polymer characterization, Lior Dassau and Jennifer Smith for assistance in mammalian cell culturing, and Mary Raven for assistance with microscopy studies. The authors are also grateful to Will Gutekunst for his helpful discussions. We also appreciate the support of UCSB Biological Nanostructures Laboratory and NRI-MCDB confocal microscopy facility (supported by NIH grant S10OD010610-01A1). D.J.L is grateful to the European Union (EU) for a Marie Curie Global Postdoctoral Fellowship. J.I.Y. acknowledges support from the NSF Graduate Research Fellowship. S.M. acknowledges support from Duncan and Mellichamp Chair and Cluster in Systems Biology and Bioengineering.

All correspondence and requests for materials should be addressed to Craig J. Hawker: hawker@mrl.ucsb.edu and H. Tom Soh: $\underline{\text { tsoh@stanford.edu }}$

\section{Author contributions}

J.N. conceived the idea, designed and performed the experiments. D.J.L. synthesized the lipidomimetic CTA compound. A.P. cultured Jurkat cells and conducted the related characterizations. J.I.Y. conducted the $\mathrm{GPCR}^{+}$yeast culturing and related characterizations. C.J.H., H.T.S., M.A.O., and S.M. supervised the study. All authors analyzed the data and co-wrote the manuscript.

\section{References}

1. Wang, B. in Cell Surface Engineering: Fabrication of Functional Nanoshells (eds. Fakhrullin, R.

F., Choi, I. S. \& Lvov, Y.) 4-27 (The Royal Society of Chemistry, 2014).

2. Ebara, M. in Chemistry of Bioconjugates: Synthesis, Characterization, and Biomedical

Applications (ed. Narain, R.) 357-368 (John Wiley \& Sons, 2014). 
3. Fakhrullin, R. F., Zamaleeva, A. I., Minullina, R. T., Konnova, S. \& Paunov, V. N. Cyborg cells: functionalisation of living cells with polymers and nanomaterials. Chem. Soc. Rev. 41, 4189-206 (2012).

4. Stephan, M. T. \& Irvine, D. J. Enhancing cell therapies from the outside in: Cell surface engineering using synthetic nanomaterials. Nano Today 6, 309-325 (2011).

5. Yang, S. H. et al. Mussel-inspired encapsulation and functionalization of individual yeast cells. $J$. Am. Chem. Soc. 133, 2795-7 (2011).

6. Boonyarattanakalin, S. et al. A synthetic mimic of human Fc receptors : defined chemical modification of cell surfaces enables efficient endocytic uptake of human immunoglobulin-G. $J$. Am. Chem. Soc. 128, 11463-11470 (2006).

7. Laughlin, S. T., Baskin, J. M., Amacher, S. L. \& Bertozzi, C. R. In vivo imaging of membraneassociated glycans in developing zebrafish. Science 320, 664-7 (2008).

8. Ferguson, M. J. \& Williams, F. Cell-surface anchoring of proteins via glycosylphosphatidylinositol structures. Ann.Rev.Biochem. 57, 285-320 (1988).

9. George, N., Pick, H., Vogel, H., Johnsson, N. \& Johnsson, K. Specific labeling of cell surface proteins with chemically diverse compounds. J. Am. Chem. Soc. 126, 8896-8897 (2004).

10. Wilson, J. T., Krishnamurthy, V. R., Cui, W., Qu, Z. \& Chaikof, E. L. Noncovalent cell surface engineering with cationic graft copolymers. J. Am. Chem. Soc. 131, 18228-9 (2009).

11. Teramura, Y. \& Iwata, H. Cell surface modification with polymers for biomedical studies. Soft Matter 6, 1081 (2010).

12. Rossi, N. A. A., Constantinescu, I., Brooks, D. E., Scott, M. D. \& Kizhakkedathu, J. N. Enhanced cell surface polymer grafting in concentrated and nonreactive aqueous polymer solutions. J. Am. 
Chem. Soc. 132, 3423-3430 (2010).

13. Wilson, J. T. et al. Cell surface engineering with polyelectrolyte multilayer thin films. J. Am. Chem. Soc. 133, 7054-7064 (2011).

14. Xu, X., Wang, B. \& Tang, R. Hybrid materials that integrate living cells: improved eco-adaptation and environmental applications. ChemSusChem 4, 1439-1446 (2011).

15. Akashi, M. M. in Cell Surface Engineering: Fabrication of Functional Nanoshells (eds. Fakhrullin, R. F., Choi, I. S. \& Lvov, Y.) 216-239 (The Royal Society of Chemistry, 2014).

16. Teramura, Y., Kaneda, Y. \& Iwata, H. Islet-encapsulation in ultra-thin layer-by-layer membranes of poly(vinyl alcohol) anchored to poly(ethylene glycol)-lipids in the cell membrane. Biomaterials 28, 4818-4825 (2007).

17. Teramura, Y., Kaneda, Y., Totani, T. \& Iwata, H. Behavior of synthetic polymers immobilized on a cell membrane. Biomaterials 29, 1345-1355 (2008).

18. Totani, T., Teramura, Y. \& Iwata, H. Immobilization of urokinase on the islet surface by amphiphilic poly(vinyl alcohol) that carries alkyl side chains. Biomaterials 29, 2878-2883 (2008).

19. Wilson, J. T. \& Chaikof, E. L. in Micro- and Nanoengineering of the Cell Surface (eds. Karp, J. M. \& Zhao, W.) 281-314 (Elsevier Inc., 2014).

20. Shih, H. \& Lin, C. C. Visible-light-mediated thiol-ene hydrogelation using eosin-Y as the only photoinitiator. Macromol. Rapid Commun. 34, 269-273 (2013).

21. Bahney, C. S. et al. Visible light photoinitiation of mesenchymal stem cell-laden bioresponsive hydrogels. Eur. Cell Mater. 22, 43-55 (2011).

22. Lilly, J. L., Romero, G., Xu, W., Shin, H. Y. \& Berron, B. J. Characterization of molecular transport in ultrathin hydrogel coatings for cellular immunoprotection. Biomacromolecules 16, 
541-9 (2015).

23. Magennis, E. P. et al. Bacteria-instructed synthesis of polymers for self-selective microbial binding and labelling. Nat. Mater. 13, 748-755 (2014).

24. Cobo, I., Li, M., Sumerlin, B. S. \& Perrier, S. Smart hybrid materials by conjugation of responsive polymers to biomacromolecules. Nat. Mater. 14, 143-159 (2014).

25. Le Droumaguet, B. \& Nicolas, J. Recent advances in the design of bioconjugates from controlled/living radical polymerization. Poly. Chem. 1, 563 (2010).

26. Xu, J., Jung, K., Atme, A., Shanmugam, S. \& Boyer, C. A robust and versatile photoinduced living polymerization of conjugated and unconjugated monomers and its oxygen tolerance. J. Am. Chem. Soc. 136, 5508-5519 (2014).

27. Xu, J., Jung, K., Corrigan, N. A. \& Boyer, C. Aqueous photoinduced living/controlled polymerization: tailoring for bioconjugation. Chem. Sci. 5, 3568 (2014).

28. Kizhakkedathu, J. N., Janzen, J., Le, Y., Kainthan, R. K. \& Brooks, D. E. Poly(oligo(ethylene glycol)acrylamide) Brushes by surface initiated polymerization: Effect of macromonomer chain length on brush growth and protein adsorption from blood plasma. Langmuir 25, 3794-3801 (2009).

29. Yoshikawa, C. et al. Fabrication of high-density polymer brush on polymer substrate by surfaceinitiated living radical polymerization. Macromolecules 38, 4604-4610 (2005).

30. Ayres, N. Polymer brushes: Applications in biomaterials and nanotechnology. Polym. Chem. 1, 769 (2010).

31. Olivier, A., Meyer, F., Raquez, J. M., Damman, P. \& Dubois, P. Surface-initiated controlled polymerization as a convenient method for designing functional polymer brushes: From self- 
assembled monolayers to patterned surfaces. Prog. Polym. Sci. 37, 157-181 (2012).

32. Krishnamoorthy, M., Hakobyan, S., Ramstedt, M. \& Gautrot, J. E. Surface-Initiated Polymer Brushes in the Biomedical Field: Applications in Membrane Science, Biosensing, Cell Culture, Regenerative Medicine and Antibacterial Coatings. Chem. Rev. 114, 10976-11026 (2014).

33. Seabrook, S., Tonge, M. P. \& Gilbert, R. G. Pulsed laser polymerization study of the propagation kinetics of acrylamide in water. J. Polym. Sci. A Polym. Chem. 43, 1357-1368 (2005).

34. Lacík, I. et al. PLP-SEC studies into the propagation rate coefficient of acrylamide radical polymerization in aqueous solution. Macromolecules (2016). doi:10.1021/acs.macromol.6b00526

35. Chua, G. B. H., Roth, P. J., Duong, H. T. T., Davis, T. P. \& Lowe, A. B. Synthesis and thermoresponsive solution properties of poly[oligo(ethylene glycol) (meth)acrylamide]s: Biocompatible PEG analogues. Macromolecules 45, 1362-1374 (2012).

36. Du, Y., Lo, E., Ali, S. \& Khademhosseini, A. Directed assembly of cell-laden microgels for fabrication of 3D tissue constructs. Proc. Natl. Acad. Sci. USA 105, 9522-9527 (2008).

37. Xu, J., Shanmugam, S., Duong, H. T. \& Boyer, C. Organo-photocatalysts for photoinduced electron transfer-reversible addition-fragmentation chain transfer (PET-RAFT) polymerization. Polym. Chem. 6, 5615-5624 (2015).

38. Bryant, S. J., Nuttelman, C. R. \& Anseth, K. S. Cytocompatibility of UV and visible light photoinitiating systems on cultured NIH/3T3 fibroblasts in vitro. J. Biomater. Sci. Polym. Ed. 11, 439-457 (2012).

39. Chiefari, J. et al. Living free-radical polymerization by reversible addition - fragmentation chain transfer : the RAFT process. Macromolecules 31, 5559-5562 (1998).

40. Shi, Y., Gao, H., Lu, L. \& Cai, Y. Ultra-fast RAFT polymerisation of poly(ethylene glycol) 
acrylate in aqueous media under mild visible light radiation at $25^{\circ} \mathrm{C}$. Chem. Commun. $1368-1370$ (2009). doi:10.1039/b821486g

41. Jewett, J. C., Sletten, E. M. \& Bertozzi, C. R. Rapid Cu-free click chemistry with readily synthesized biarylazacyclooctynones. J. Am. Chem. Soc. 132, 3688-3690 (2010).

42. Baskin, J. M. et al. Copper-free click chemistry for dynamic in vivo imaging. Proc. Natl. Acad. Sci. U. S. A. 104, 16793-16797 (2007).

43. Rowe-Konopacki, M. D. \& Boyes, S. G. Synthesis of surface initiated diblock copolymer brushes from flat silicon substrates utilizing the RAFT polymerization technique. Macromolecules $\mathbf{4 0}$, 879-888 (2007).

44. Zammarelli, N., Luksin, M., Raschke, H., Hergenröder, R. \& Weberskirch, R. 'grafting-from' Polymerization of PMMA from stainless steel surfaces by a raft-mediated polymerization process. Langmuir 29, 12834-12843 (2013).

45. Chen, Y., Kamlet, A. S., Steinman, J. B. \& Liu, D. R. A biomolecule-compatible visible-lightinduced azide reduction from a DNA-encoded reaction-discovery system. Nat. Chem. 3, 146-153 (2011).

46. Sen, M. Y. \& Puskas, J. E. Green polymer chemistry: Telechelic poly(ethylene glycol)s via enzymatic catalysis. J. Polym. Sci. A Polym. Chem. 45, 4300-8 (2007).

47. Ladmiral, V., Legge, T. M., Zhao, Y. \& Perrier, S. 'Click' chemistry and radical polymerization: Potential loss of orthogonality. Macromolecules 41, 6728-6732 (2008).

48. Hong, D. et al. Organic/inorganic double-layered shells for multiple cytoprotection of individual living cells. Chem. Sci. 6, 203-208 (2015).

49. Lesage, G. \& Bussey, H. Cell wall assembly in Saccharomyces cerevisiae. Microbiol. Mol. Biol. 
$\operatorname{Rev~70,~317-43~(2006).~}$

50. Cabib, E., Roh, D.-H., Schmidt, M., Crotti, L. B. \& Varma, A. The yeast cell wall and septum as paradigms of cell growth and morphogenesis. J. Biol. Chem. 276, 19679-19682 (2001).

51. Lamport, D. T. A. Cell wall metabolism. Annu. Rev. Plant Physiol. 21, 235-270 (1970).

52. O’Malley, M. A., Lazarova, T., Britton, Z. T. \& Robinson, A. S. High-level expression in Saccharomyces cerevisiae enables isolation and spectroscopic characterization of functional human adenosine A2a receptor. J. Struc. Bio. 159, 166-178 (2007).

53. Kim, B. S., Lee, H. I., Min, Y., Poon, Z. \& Hammond, P. T. Hydrogen-bonded multilayer of pHresponsive polymeric micelles with tannic acid for surface drug delivery. Chem. Commun. 4194-6 (2009).

54. Kim, K. et al. TAPE: A medical adhesive inspired by a ubiquitous compound in plants. Adv. Func. Mater. 25, 2402-2410 (2015).

55. Kozlovskaya, V. et al. Hydrogen-bonded LbL shells for living cell surface engineering. Soft Matter 7, 2364 (2011).

56. Selden, N. S. et al. Chemically programmed cell adhesion with membrane-anchored oligonucleotides. J. Am. Chem. Soc. 134, 765-8 (2012). 